\title{
Strategi Pengelolaan Keuangan bagi Bisnis Batik Besurek Bengkulu
}

\author{
Eti Arini, Yudi Pratama Putra, Ratnawili, Budi Astuti, Meilaty Finthariasari* \\ Universitas Muhammadiyah Bengkulu \\ *mheyfinta@umb.ac.id
}

\begin{abstract}
Abstrak
Permasalahan yang dihadapi UMKM Batik yang bernama Kampung Batik Betungan adalah berkaitan dengan pengelolaan keuangan. Berdasarkan permasalahan yang dihadapi para pelaku bisnis batik serta dalam rangka pemberdayaan pelaku UMKM Kelurahan Betungan Kota Bengkulu yang bertujuan untuk meningkatkan pengetahuan pengelolaan keuangan dan permodalan serta membantu dalam mengkoordinasi antara pihak terkait dengan UMKM Kelurahan Betungan Kota Bengkulu dalam upaya perolehan modal dan persyaratan yang perlu dipenuhi UMKM dalam perolehan modal. Adapun kegiatan pengabdian yang dilakukan oleh tim adalah melakukan pelatihan/ penyuluhan untuk meningkatkan pengetahuan dan pemahaman tentang pentingnya manajemen keuangan, serta melakukan pelatihan/ penyuluhan untuk meningkatkan pengetahuan dan pemahaman tentang perencanaan modal, pengelolaan modal dan pendistribusian keuntungan dan pencatatan keuangan.
\end{abstract}

Kata Kunci: pengelolaan keuangan, bisnis Batik Besurek

\section{Financial Management Strategy for Batik Besurek Bengkulu Business}

\begin{abstract}
The problems faced by Batik SMEs named Kampung Batik Betungan are related to financial management. Based on the problems faced by batik business people and in the context of empowering MSME actors in Betungan Village, Bengkulu City which aims to increase knowledge of financial and capital management and assist in coordinating between parties related to MSMEs in Betungan Village, Bengkulu City in an effort to obtain capital and the requirements that MSMEs need to meet in capital acquisition. The service activities carried out by the team are conducting training / counseling to increase knowledge and understanding of the importance of financial management, as well as conducting training / counseling to increase knowledge and understanding of capital planning, capital management and distribution of profits and financial records.
\end{abstract}

Keywords: financial management, Batik Besurek business

\section{PENDAHULUAN}

Salah satu budaya yang terkenal dan juga telah mendarah daging dii masyarakat Indonesia adalah kain batik. Batik merupakan hasil karya bangsa Indonesia yang merupakan perpaduan antara seni dan teknologi oleh leluhur bangsa Indonesia. Batik Indonesia telah berkembang hingga pada suatu tingkatan yang tak ada bandingannya baik dalam desain/motif maupun prosesnya. Corak ragam yang ada pada batik memiliki makna dan filosofi akan terus digali dari berbagai adat istiadat maupun budaya yang berkembang di Indonesia (Nugroho, 2020). Motif Batik menurut Kamus Besar Bahasa Indonesia, motif adalah corak atau pola. Motif adalah suatu corak yang di bentuk sedemikian rupa hingga menghasilkan suatu bentuk yang beraneka ragam. Dengan semakin pesatnya teknologi dalam membatik serta banyaknya bermunculan pebisnis batik menyebabkan para pelaku lama di bisnis batik atau pengrajin batik harus melalukan inovasi baik di bidang teknologi berproduksi, maupun corak dan warna serta kualitas bahan/kain batik tersebut.

Provinsi Bengkulu yang terletak di pulau Sumatera juga memiliki budaya kerajinan Batik yang bernama Batik Besurek. Sama halnya dengan batik lainnya, Batik Besurek juga 
Vol. 2, No. 3,

November

2021

pp. $341-348$

e-ISSN:

2722-2004

Financial

Management

Strategy for

Batik Besurek

Bengkulu

\section{Business}

Eti Arini,

Y. P. Putra,

Ratnawili,

Budi Astuti,

M. Finthariasari

di tuliskan pada kain berbahan dasar katun atau sutra ini menjadi populer bagi para turis lokal maupun mancanegara yang berkunjung ke Kota Bengkulu. Pada tahun 2015 Batik Besurek telah ditetapkan sebagai warisan Budaya Takbenda bagi Bengkulu (Wikipedia, 2021). Corak kaligrafi sangat kental di kain besurek dan menjadi penanda akulturasi budaya lokal dan Arab. Ada tujuh jenis motif dasar batik kain besurek. Yakni, motif kaligrafi Arab, rembulan, kembang melati. Selain itu ada juga motif burung kuau, pohon hayat, kombinasi kembang cengkih dan kembang cempaka, serta perpaduan relung paku dan burung punai. Warna-warna yang biasa digunakan dalam batik besurek, umumnya merah, merah manggis, dan merah kecoklatan (Herlina, 2021).

Kegiatan pengabdian saat ini didasari oleh hasil observasi dan wawancara yang telah dilakukan oleh TIM Abdimas, permasalahan yang dihadapi UMKM kelompok batik Kelurahan Betungan Kota Bengkulu adalah sebagai berikut :

1. Belum dapat terealisasikan potensi yang dimiliki UKM kelompok batik Kelurahan Betungan Kota Bengkulu karena minimnya pengetahuan manajemen keuangan/permodalan.

2. Belum adanya kesadaran UKM kelompok batik Kelurahan Betungan Kota Bengkulu dalam rangka pembenahan manajemen keuangan yang tujuan akhirnya adalah agar dapat menyelesaikan masalah keuangan bisnis terutama berkaitan dengan masalah permodalan.

3. Belum ada pihak yang memfasilitasi UMKM kelompok batik Kelurahan Betungan Kota Bengkulu dalam rangka merealisasikan potensi yang di miliki sehingga dapat membantu dalam mengatasi masalah permodalan bagi bisnis ini untuk meningkatkan kinerja keuangan.

4. Belum ada koordinasi yang baik antara pihak terkait maupun dengan UMKM kelompok batik Kelurahan Betungan Kota Bengkulu dalam upaya perolehan modal dan persyaratan yang perlu dipenuhi UMKM dalam perolehan modal.

Berdasarkan permasalahan yang dihadapi para pelaku bisnis batik serta dalam rangka pemberdayaan pelaku UMKM Kelurahan Betungan Kota Bengkulu yang bertujuan untuk meningkatkan pengetahuan pengelolaan keuangan dan permodalan serta membantu dalam mengkoordinasi antara pihak terkait dengan UMKM Kelurahan Betungan Kota Bengkulu dalam upaya perolehan modal dan persyaratan yang perlu dipenuhi UMKM dalam perolehan modal melalui :

1. Melakukan pelatihan/penyuluhan agar para pelaku bisnis yang dimaksudkan dapat meningkatkan pengetahuan dan pemahaman mengenai arti pentingnya manajemen keuangan.

2. Melakukan pelatihan/penyuluhan agar para pelaku bisnis yang dimaksudkan supaya dapat meningkatkan pengetahuan dan pemahaman tentang materi perencanaan modal, materi pengelolaan modal, dan materi pendistribusian keuntungan dan pencatatan keuangan.

\section{METODE PELAKSANAAN}

Pendekatan yang dipakai dalam kegiatan abdimas ini yaitu 1) Metode memberikan Ceramah. Pada kesempatan ini tim abdimas memberikan ceramah kepada para pebisnis batik Kelurahan Betungan Kota Bengkulu yang bertempat di salah satu toko batik bernama Kampung Batik Betungan. Materi ceramah 
yang diberikan tentang pentingnya manajemen bagi perkembangan UMKM Batik. 2) Metode pelatihan dengan cara demonstrasi. Tim Abdimas akan melatih dan mendemonstrasikan tentang bagaimana cara mengelola dan merencanakan permodalan, sistem pelaporan keuangan, serta memberikan penjabaran mengenai alat alat yang diperlukan untuk membuat laporan keuangan dalam bisnis. Sedangkan metode perolehan data dalam pengabdian ini yang dilakukan oleh Tim Abdimas tentang Manajemen Keuangan adalah berupa diskusi dan tanya jawab dengan peserta pelatihan tentang permasalahan yang dihadapi serta terkait dengan bagaimana menemukan solusinya.

\section{HASIL DAN PEMBAHASAN}

Batik Besurek menjadi dikenal oleh masyarakat Bengkulu yaitu berawal dari para pedagang Arab dan para pekerja asal India pada abad ke-17. Seiring dengan perkembangannya, Batik Besurek yang merupakan seni membuat motif pada kain yang dipadukan dengan tradisi Indonesia dan memiliki ciri khas Bengkulu. Kisah cerita dinamakan Batik Besurek adalah karena batik ini menggunakan motif-motif bertuliskan kaligrafi Arab. Besurek berasal dari bahasa Melayu dengan dialek Bengkulu yang artinya bersurat atau tulisan. Motif besurek ini telah berkembang dan menjadi kebanggaan Bengkulu yang dilestarikan keberadaannya. Kain bermotifkan besurek sering kali digunakan sebagai pakaian wajib bagi pelajar sekolah dasar hingga sekolah menengah atas, pakaian wajib bagi Pegawai Negeri Sipil sejak tahun 1990. Pemerintah menetapkan aturan seragam ini di Provinsi Bengkulu. Hal ini adalah bentuk salah satu upaya pemerintah daerah di Provinsi Bengkulu dalam menjaga, mengembangkan, dan pelestarian Batik Besurek.

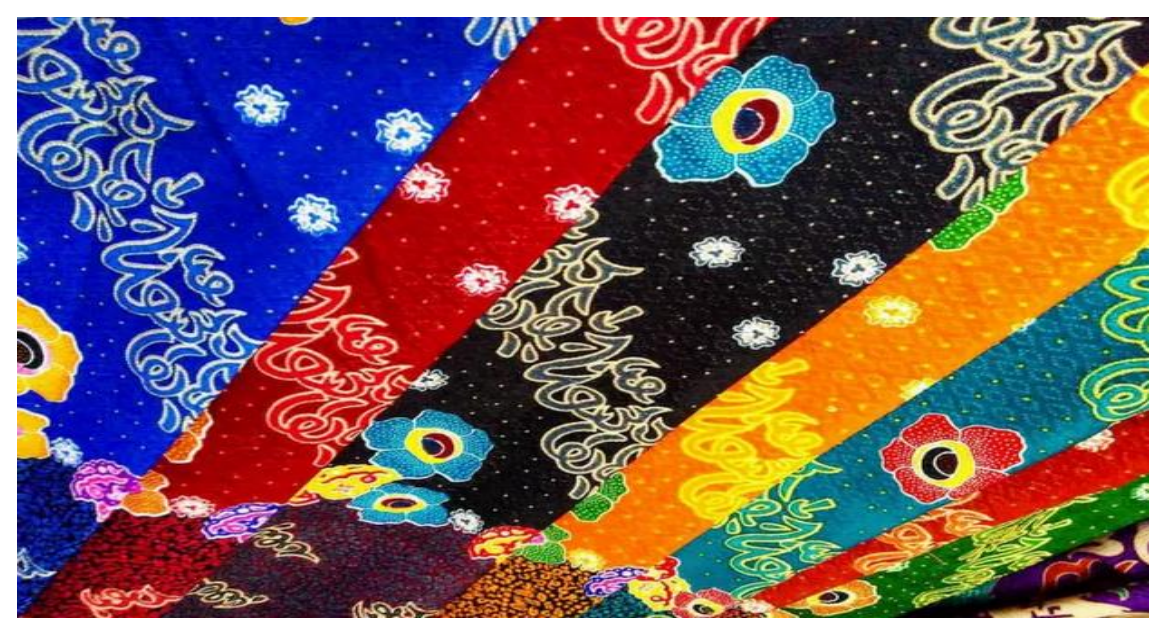

Sumber: Novitasari (2021)

Gambar 1. Kain Batik Besurek Bengkulu 
Vol. 2, No. 3,

November

2021

pp. 341-348

e-ISSN:

2722-2004

\section{Financial}

Management

Strategy for

Batik Besurek

Bengkulu

Business

Eti Arini,

Y. P. Putra,

Ratnawili,

Budi Astuti,

M. Finthariasari

\section{Motif Batik Bengkulu}

Berikut ini beberapa motif yang biasa digunakan dalam Batik Besurek (Wikipedia, 2021):

1. Motif kaligrafi dirancang dengan menggunakan tulisan motif yang diambil dari huruf-huruf kaligrafi. Batik Besurek yang digunakan pada saat upacara adat, bertuliskan huruf Arab yang dapat dibaca, serta memiliki makna. Namun sebagian besar hanya berbentuk hiasan mirip huruf Arab yang tidak memiliki makna yang jelas di dalamnya.

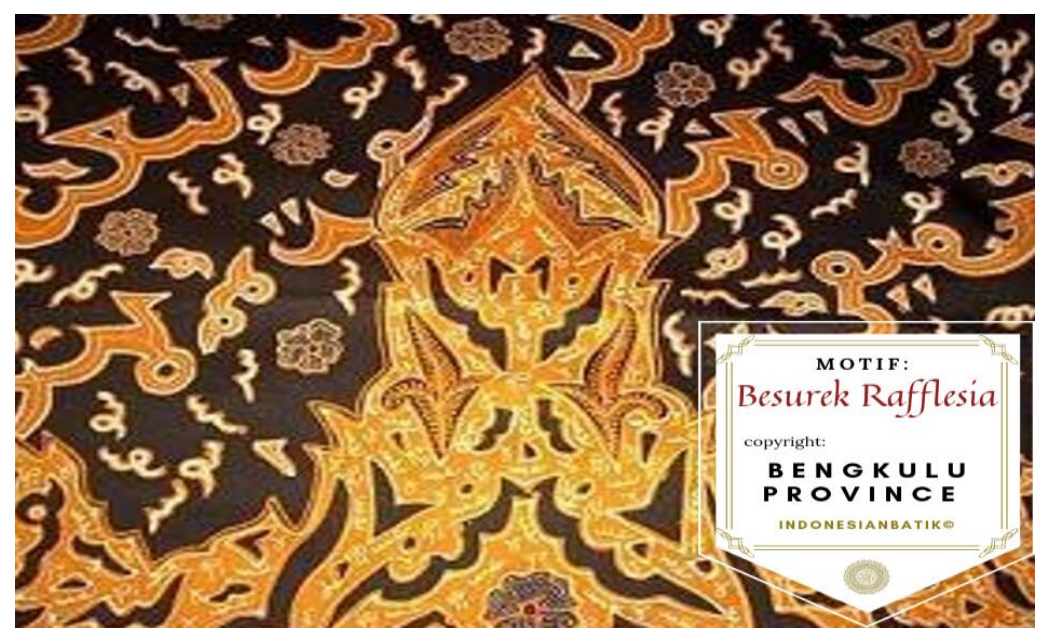

Sumber: Batik (2020)

Gambar 2. Kain Batik Besurek Bengkulu

2. Motif raflesia merupakan motif berdesain/bergambar padma raksasa khas Bengkulu. Di mana motif ini menggambarkan bunga raflesia yang merupakan bunga khas Bengkulu. Motif ini merupakan motif utama kain besurek setelah motif kaligrafi.

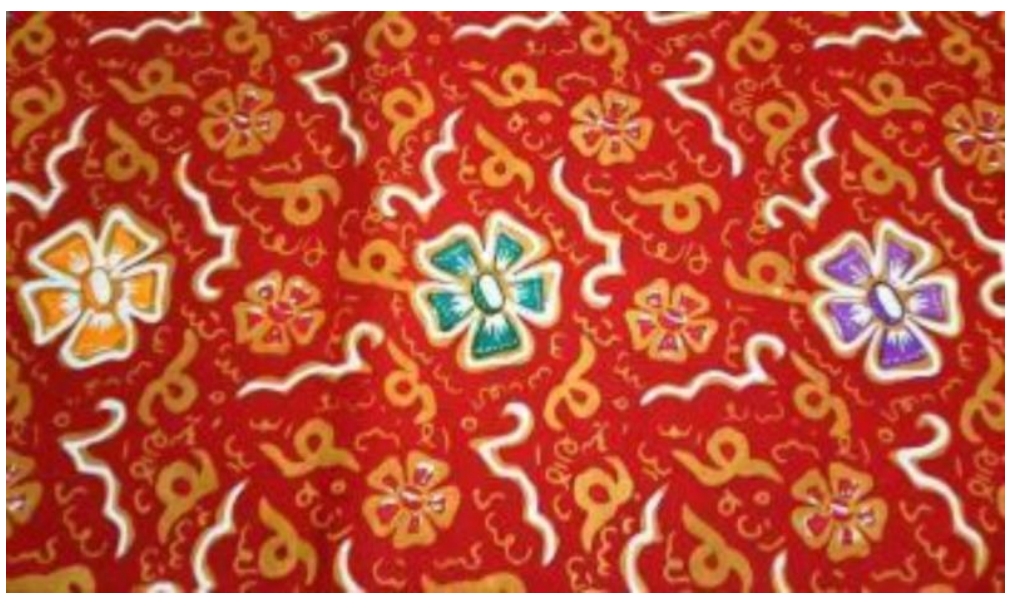

Sumber: Julita (2021)

Gambar 3. Kain Batik Besurek Bengkulu

3. Motif burung kuau merupakan motif besurek yang bergambarkan burung kuau seperti rangkaian huruf-huruf kaligrafi. 
KANGMAS: Karya Ilmiah Pengabdian Masyarakat, 2 (3), November 2021 - 345 http://journal.neolectura.com/index.php/Kangmas

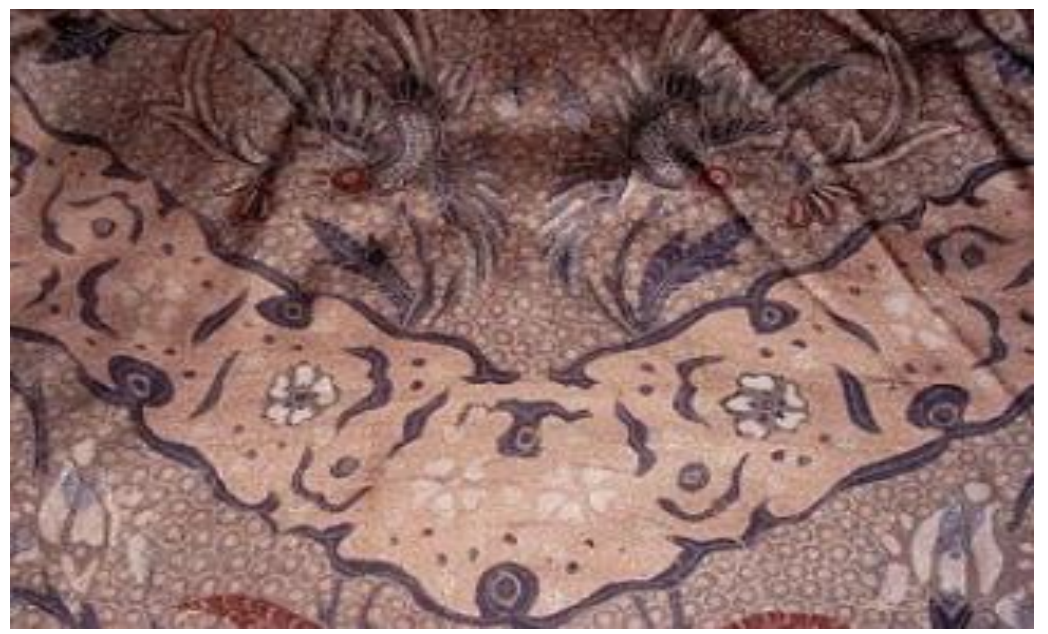

Sumber: Novitasari (2021)

Gambar 4. Kain Batik Besurek Bengkulu

4. Motif relung paku adalah motif Batik Besurek yang dituliskan dengan desain meliuk-liuk seperti tumbuhan paku.

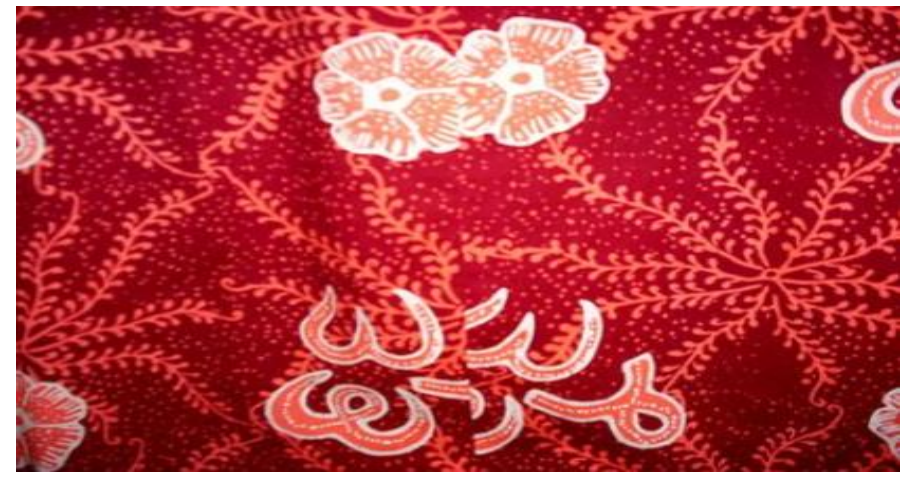

Our focus: Social Service journal published by Neolectura, issued three times in one year. KANGMAS is a scientific publication media in the form of conceptual paper and field research related to social service work. It is hoped that KANGMAS can become a media for academics and researchers to publish their social service work and become a reference source for the development of social and humanity.

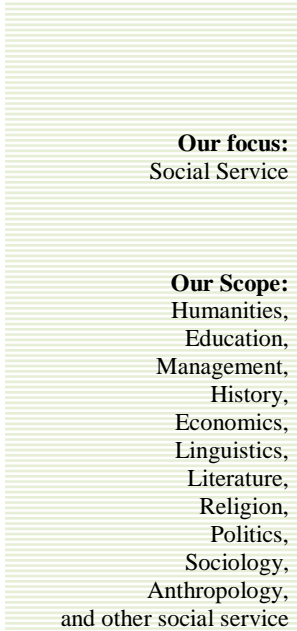

and other social service works.

Sumber: Novitasari (2021)

Gambar 5. Kain Batik Besurek Bengkulu

5. Motif rembulan adalah motif yang berdesain paduan antara gambar bulan dengan motif kaligrafi.

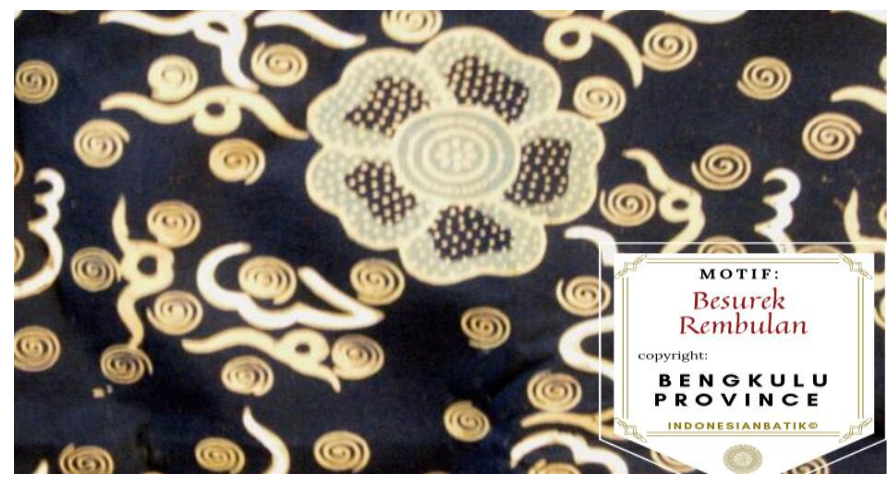

Sumber: (Batik, 2020)

Gambar 6. Kain Batik Besurek Bengkulu 
Vol. 2, No. 3,

November

2021

pp. 341-348

e-ISSN:

2722-2004

Financial

Management

Strategy for

Batik Besurek

Bengkulu

Business

Eti Arini,

Y. P. Putra,

Ratnawili,

Budi Astuti,

M. Finthariasari

Tim Abdimas melakukan serangkaian kegiatan seperti: pertama, memberikan solusi pada permasalahan yang ada dengan melakukan kegiatan penyuluhan/ pelatihan singkat terkait manajemen keuangan yang diharapkan dapat memberikan solusi terhadap permasalahan yang ada pada UMKM Batik.

\section{Strategi Pengelolaan Dana}

Para pelaku bisnis sedapat mungkin memiliki buku catatan kas masuk dan keluar. Hal ini sangat perlu dan dianjurkan agar dapat menerapkan prinsipprinsip manajemen keuangan. Berikut beberapa prinsip dasar manajemen keuangan untuk UKM.

1. Pisahkan Uang Pribadi dan Uang Usaha (UP vs U2)

Kegiatan ini memang mudah dilakukan namun banyak pelaku bisnis membuat kesalahan yaitu sering mencampur adukkan uang usaha dengan uang pribadi. Hal ini terjadi dengan alasan usaha masih kecil, sehingga pelaku bisnis berpikir singkat dan terkesan menyepelekan jika mencampur uang usaha dengan uang pribadi. Untuk poin ini yang paling penting adalah bersikaplah disiplin dalam menerapkan pemisahan keuangan pribadi dan keuangan usaha. Kuncinya adalah disiplin dan komitmen.

\section{Rencanakan Penggunaan Uang (RPU)}

Merencanakan penggunaan uang dengan sebaik mungkin adalah hal yang penting bahkan saat memiliki modal lebih banyak dari yang diperkirakan. Jika tidak memiliki perencanaan yang matang, maka akan menemukan kondisi sulit keuangan. Sesuaikan rencana pengeluaran dengan target-target penjualan dan penerimaan kas. Lakukan analisa cost and benefit untuk meyakinkan bahwa penggunaan uang bisnis tidak sia-sia dan dapat memberikan return yang menguntungkan serta dapat meningkatkan profit usaha.

\section{Buat Buku Pencatatan Keuangan (BKM \& BKK)}

Dalam mengelola bisnis, manajemen harus memiliki Buku Kas Masuk (BKM) dan Buku Kas Keluar (BKK) yang mencatat keluar masuknya uang, mencocokkan saldo uang secara fisik dengan catatan harian. Hal ini berguna untuk mengontrol transaksi uang dan memastikan tidak ada uang yang terselip. Tahapan selanjutnya adalah tingkatkan kemampuan administrasi untuk mencatat penjualan dan biaya-biaya yang ada, mencatat saldo-saldo hutang piutang, persediaan, serta beberapa aset tetap yang dimiliki. Jika mampu, gunakan sistem komputer untuk mempermudah proses pencatatan dan lebih rapi. Pelan-pelan juga dapat diterapkan sistem akuntansi yang lebih memadai untuk dapat menampilkan laporan keuangan usaha, minimal dalam bentuk neraca dan laba/rugi. Laporan keuangan terdiri dari cash flow (uang masuk/keluar), catatan omzet harian, mingguan dan bulanan, dan catatan pembelian.

4. Manfaatkan Pihak Ketiga atau Gunakanlah Software

Agar bisnis lebih tertata jika dapat pelan-pelan terapkan penggunaan software manajemen keuangan sederhana untuk usaha kecil. Beberapa Hal yang 
perlu disiapkan adalah buatlah 5 buku akun atau buku rekening atau bahasa mudahnya buku catatan terpisah yang mencatat tiap-tiap transaksinya.

a. Buku Arus Kas atau buku kas; Berisikan hanya catatan uang keluar dan masuk saja.

b. Buku Persediaan Barang; Berisikan tentang catatan setiap pertambahan barang masuk yang kita lakukan karena ada kegiatan pembelian barang dari supplier atau pemasok barang / bahan baku produksi.

c. Buku Pembelian dan Penjualan; Berisikan tentang catatan uang keluar karena pembelian barang yang kita lakukan. Catatan ini berfungsi sebagai kontrol belanja bisnis (seberapa besar pembelian dan berapa besar penjualan (omzet), dan selisihnya langsung menjadi laba kotor sebelum dikurangi biaya-biaya).

d. Buku Hutang Piutang; Biasanya sudah memiliki catatan hutang pelanggan dan piutang ke pihak supplier.

e. Buku Biaya dan pendapatan lain selain dari penjualan barang/jasa kita; Setiap catatan biaya-biaya dan pendapatan lain harus dikumpulkan dalam sebuah akun/buku tersendiri. Hal Ini penting dilakukan untuk mendapatkan data laba bersih dalam berbisnis. Pencatatan biaya seperti biaya listrik, telepon, pengemis dsb. Sedangkan pendapatan lain contohnya menjual kardus bekas, parkir dsb.

5. Menghitung Keuntungan dengan tepat

6. Putar Arus Kas

7. Awasi Harta, Hutang dan Modal

8. Sisihkan Keuntungan untuk Pengembangan Usaha

\section{Permodalan Usaha}

Adapun strategi mendapatkan permodalan, yaitu:

1. Untuk meminimumkan risiko, awali usaha dengan modal sendiri (modal keluarga).

2. Membuat legalitas usaha.

3. Membuat rencana bisnis dengan matang.

Beberapa cara menembus perbankan untuk mendapatkan pemodalan:

1. Menyesuaikan permohonan kredit dengan pasar sasaran bank, berkas permohonan akan ditolak, jika tidak sesuai dengan pasar sasaran.

2. Menganalisis kredit: Identitas permohonan, tujuan permohonan kredit, riwayat hubungan bisnis dengan bank (sistem informasi debitur BI).

3. Menganalisis $5 \mathrm{C}$ kredit (charakter, capacity, capital, condition dan collateral).

\section{Menyiasati Kredit Usaha kecil}

1. Bagi usaha baru dimulai, sebaiknya menghindari pembiayaan dari bank

2. Apabila bisnis ingin mengajukan kredit pada bank, maka harus memperbaiki manajemen internal. 
Vol. 2, No. 3,

November

2021

pp. 341-348

e-ISSN:

2722-2004

Financial

Management

Strategy for

Batik Besurek

Bengkulu

\section{Business}

Eti Arini,

Y. P. Putra,

Ratnawili,

Budi Astuti,

M. Finthariasari

3. Dalam rangka keberlangsungan bisnis, perlu mempertimbangkan resiko kredit perbankan.

4. Pelaku bisnis sangat perlu mencari informasi yang valid, sebelum memilih bank dan jenis kredit.

\section{PENUTUP}

Kegiatan pengabdian dengan metode ini, mendapatkan respons positif dari berbagai pihak, baik para pelaku UMKM batik, pengrajin batik maupun pemerintah di Kota Bengkulu. Penyuluhan/pelatihan yang dilakukan saat kegiatan pengabdian kepada masyarakat tentang strategi pengelolaan dana dan jenis-jenis permodalan serta strategi untuk mendapatkan modal (manajemen Keuangan) diharapkan dapat menjadi solusi bagi permasalahan yang selama ini muncul bagi bisnis batik di Kota Bengkulu. Dengan harapan kegiatan pengabdian kepada masyarakat ini dapat dilakukan secara kontinu dan berkelanjutan agar UMKM batik dapat membenahi manajemen keuangan dan motivasi dalam menjalankan bisnisnya sehingga dapat meningkatkan kinerja keuangan UMKM batik.

\section{DAFTAR PUSTAKA}

Batik, Iw. (2020). Besurek Raflesia. Iwarebatik.Org. https://www.iwarebatik.org/besurek-rafflesia/?lang=id

Herlina, B. (2021). Pengusaha Batik Besurek di Bengkulu Bertahan di Tengah Gempuran Zaman. DW.Com. https://www.dw.com/id/kain-batik-tulisbesurek-dari-bengkulu/a-59380647

Julita, V. intan. (2021). Sejarah Batik Besurek Khas Bengkulu! https://Osc.Medcom.Id/. https://osc.medcom.id/community/sejarahbatik-besurek-khas-bengkulu-2855

Novitasari, C. (2021). BATIK BENGKULU | Sejarah, Motif, Gambar dan Penjelasan. Pelajarindo.Com. https://pelajarindo.com/batik-bengkulusejarah-motif/

Nugroho, H. (2020). Pengertian Motif Batik dan Filosofinya. Kementerian Perindustrian Republik Indonesia. 